\title{
Study on the load bearing properties of eccentric assembled foundations of transmission lines
}

\author{
Cheng Yongfeng ${ }^{1, \mathrm{a}}$, Zheng Weifeng ${ }^{1, \mathrm{~b}^{*}}$, Zhao Qingbin ${ }^{2}$, Zhang Hongqiao ${ }^{2}$ \\ ${ }^{1}$ Chine Electric Power Research Institute, Beijing 100192, China \\ ${ }^{2}$ Sichuan Electric Power Design \& Consulting Co., Ltd., Chengdu 610016, China \\ a Email: cyf@epri.sgcc.com.cn \\ ${ }^{b}$ Email: zhengwf@epri.sgcc.com.cn
}

Keywords: power transmission line; eccentric assembled foundation; pyramid scaffold; cross-shaped welded plate; real model test

Abstract: The assembled foundations of transmission lines can effectively promote the standardization, modularization and mass productions of tower foundations. Meanwhile, they can ensure a higher quality, improve the efficiency and mechanization level of construction, and make innovations in the construction mode of transmission lines. Through modifications and improvements in layout type of scaffolds and connection mode, the eccentric assembled foundation consisting of concrete laths and angle steel scaffolds can make the force bearing on foundation more reasonable, and effectively save the steel consumption. Real-model tensile and compressive tests were conducted on the hard clay along the direction of main member and diagonal member of the tower leg. Test results further confirm the foundation's favorable bearing performance, which provides a support for its engineering applications.

\section{Introduction}

The construction period of the tower foundation of power transmission lines accounts for roughly $50 \%$ of the project duration. The transport volume and cost for the construction of tower foundations occupy $60 \%$ and $35 \%$ of those of the whole project, respectively. The transmission line foundations have various types. In some transmission line projects with harsh natural conditions such as high attitude, water deficit, and difficult sand and stone collections, long transport distance and tight schedule, the assembled foundations are widely adopted owing to their favorable economic and social benefits ${ }^{[1-4]}$. The assembled foundations can effectively promote the standardization, modularization and mass production of tower foundations. Besides, they can guarantee a higher quality, enhance the construction efficiency and mechanization level, and make innovations in the construction mode of transmission lines ${ }^{[5]}$.

In terms of connection mode, the assembled foundations are classified into four main types: 1) solid joint of straight column, 2) straight column splicing, 3) direct footing burial, and 4) direct insertion of main member. In terms of material selection, there are 1) all-metal assembled foundations, 2) precast concrete assembled foundations, and 3) those consisting of concrete laths and section steels ${ }^{[6]}$.

Since the tower foundations are frequently subjected to the joint action of uplifting load and horizontal load, the bending moment of the foundation slab can be remarkably reduced by adopting an eccentric structure. Thereby, the force condition of the foundation can be significantly improved ${ }^{[7,8]}$. The eccentric assembled foundations consisting of concrete laths and angle steel scaffold (hereinafter referred to as the eccentric assembled foundations) combines the characteristics of assembled foundation and eccentric structure. However, their mechanical properties and load bearing characteristics are still unclear.

Therefore, we conducted the real model tests of eccentric assembled foundations in the clay. By measuring the variation rules of the top displacement of the foundations and the surface vertical displacement, the anti-pulling performance and the bearing mechanism of eccentric assembled foundations were analyzed. The analysis results provide technical supports for the popularization of eccentric assembled foundations in transmission lines. 


\section{Test scheme}

Overview of the test site. The test site is located at Liang Village, Fangshan District, Beijing. The local soil belongs to the back-filled tough clay, the primary physical and mechanical parameters of which are listed in Table 1. The light dynamic penetration test results indicate that, the back-filled clay at the depth of $1.0 \sim 2.0$ mhas favorable compaction effect. The shallow plate loading test results indicate that, the characteristic value fak of the bearing capacity of the surface soil is $145 \mathrm{kPa}$.

Table 1 Main Physical and mechanical parameters of backfill clay

\begin{tabular}{ccccc}
\hline $\begin{array}{c}\text { Bulk density } \\
\mathrm{V} / \mathrm{kN} / \mathrm{m}^{3}\end{array}$ & Moisture content & Cohesion & Internal friction angle & \multicolumn{2}{c}{ Plasticity index } \\
\hline 18.90 & $1 \%$ & $\varphi / \mathrm{kPa}$ & $\varphi /{ }^{\circ}$ & $I_{p}$ \\
\hline
\end{tabular}

Structure and size of the test foundations. Fig. 1 shows the structure of the eccentric assembled foundation. In terms of structural style, the section steel scaffold is inclined; the projection point of the scaffold vertex onto the basement fails to coincide with the basement center, but is eccentric along the direction of the bottom slab's symmetry axis which is parallel to the longitudinal axis of beam. In terms of connection mode, the section steel scaffolds and the upper tower legs are characterized by a plug-in-like connection, i.e., the main members and diagonal members of tower legs are connected to four landing legs of the foundation scaffold with the cross-shaped welded plates and bolts. This connection mode is simple, and the tower leg plate and the connection steel plate at the top of scaffold are saved. Through the improvements and modifications in the layout type of scaffolds and connection mode, the eccentric assembled foundation is more reasonable in force bearing and the steel usage can be effectively saved.

The foundation has a burial depth of $3 \mathrm{~m}$. The foundation slab, with the size of $3.12 \mathrm{~m} \times 3.12 \mathrm{~m}$, consists of 7 concrete laths and 2 concrete beams, in which the lath is $300 \mathrm{~mm}$ in width and the maximum clear distance between slabs is $170 \mathrm{~mm}$. The lath and beam are connected by bolts. The foundation scaffold is composed of 4 main members (L110 $\times 10$ section steel) and 8 diagonal members (L65 $\times 5$ section steel). The section steel scaffolds are connected to the main and diagonal members of tower leg with the cross-shaped welded plates and bolts.

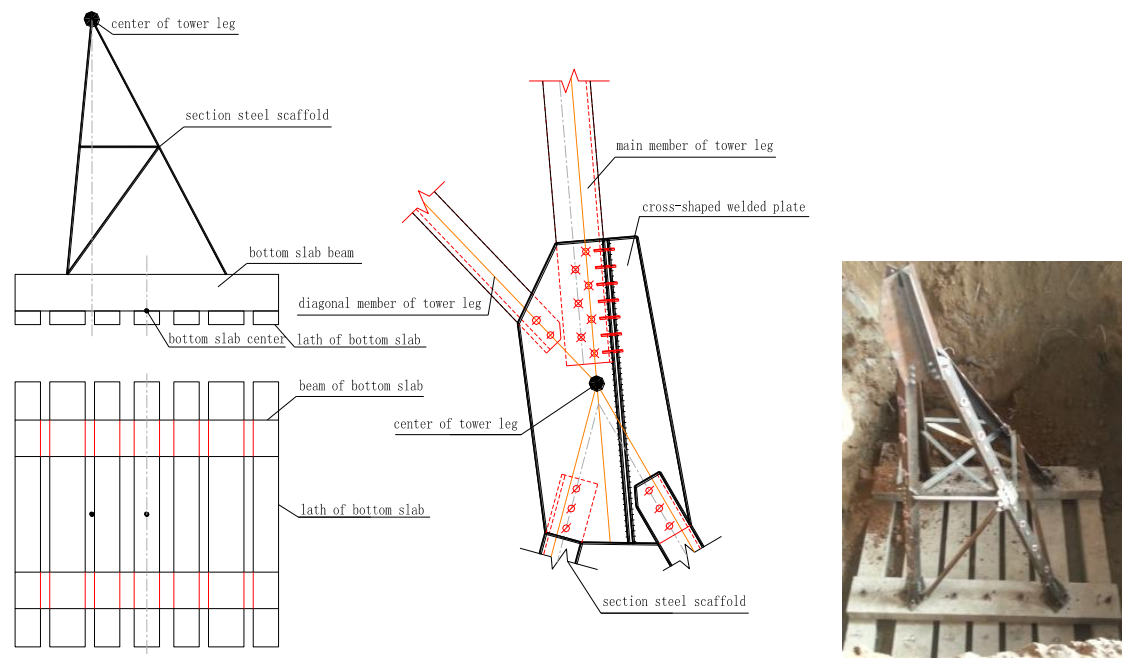

(a) eccentric structure

(b) connection mode

(c) foundation construction

Fig. 1 Schematic of the eccentric assembled foundation

Tests under the loading conditions. The real mode tests were conducted under two operating conditions that the foundation was pulled and compressed along the direction of tower leg angle. Through the loading on the main and diagonal members of tower leg along three directions, the forces of the upper tower on the foundation were simulated. Table 1 lists the designed loading values of the foundation.

Loading system in the test. Fig. 2 shows the loading system in the test. Fig. 2 (a) shows the tensile system whose load is applied along the direction of tower leg. In this system, the main member of tower leg is loaded by the jack, while the two diagonal members are loaded by a device consisting of pulleys, steel wire rope and 
tension sensor. Fig. 2 (b) shows the compressive system whose load is applied along the direction of tower leg, in which the main and diagonal members of tower leg are loaded by the jack.

Table 2 Maximum forces on the foundation

\begin{tabular}{|c|c|c|c|}
\hline \multirow{2}{*}{ Loading condition } & \multicolumn{3}{|c|}{ Internal forces of the main and diagonal member of tower leg / $\mathrm{kN}$} \\
\cline { 2 - 4 } & main member of tower leg & front diagonal member of tower leg & lateral diagonal member of tower leg \\
\hline Tensile tests & 560 & 54 & 54 \\
\hline Compressive tests & -720 & -55 & -55 \\
\hline
\end{tabular}

(a) Tensile system

(b) Compressive sy stem

Fig. 2 Tensile and compressive loading systems with the load applied along the direction of tower leg

\section{Test results and analyses}

Tensile tests with the loading direction according with the angle of tower leg. Fig. 3 presents the load-displacement curves of the tensile tests whose load accords with the angle of tower leg. It can be observed from Fig. 3 (a) and (b) that, at the initial stage of loading, the load displacement is almost linear; an obvious inflection point appears when the main member is loaded at $616 \mathrm{kN}$ and the diagonal member at 59 $\mathrm{kN}$. At the late stage of loading, the variation rate of displacement increases significantly. The ultimate bearing capacity of the foundation is considered to be $616 \mathrm{kN}$ in the direction of main member and $59 \mathrm{kN}$ in the direction of diagonal member. The two values are 1.1 times that of the design values, which means the foundation satisfies the design requirements. Fig. 3 (c) shows the load-displacement curves at the surface displacement monitoring points, from which we can observe that the surface displacement at the center of the bottom slab is greatest and decreases towards both sides.
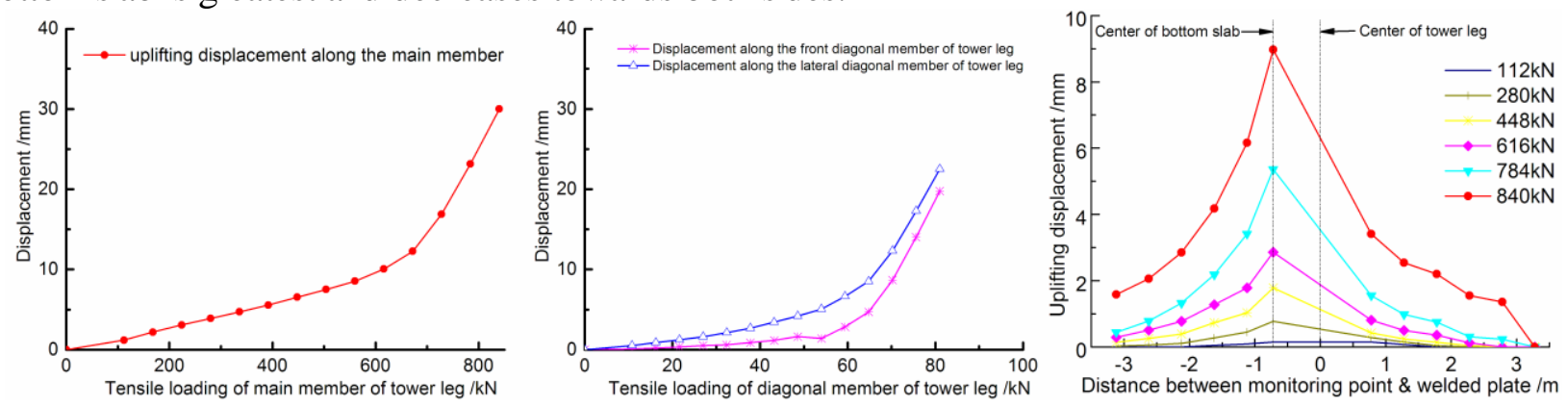

(a) Main member of tower leg

(b) Diagonal member of tower leg

(c) Surface displacement monitoring point

Fig. 3 Load-displacement curves of the tensile tests with loading direction in accord with the angle of tower leg

Compressive tests with the loading direction according with the angle of tower leg. Fig. 4 shows the load-displacement curves of the compressive tests whose loading direction is in accord with the angle of tower leg. As shown in Fig. 4 (a) and (b), the load-displacement curves are basically linear; the maximum bearing capacities of the foundation are $1296 \mathrm{kN}$ (for the main member) and $99 \mathrm{kN}$ (for the diagonal member), which are 1.8 times that of the design values. It suggests that the foundation satisfies the design requirements. Fig. 4 (c) shows the load-displacement curves at the surface displacement monitoring points. It can be seen that the maximum settlement point is located at the center of bottom slab rather than the center of top tower leg, and the displacement decreases gradually towards both sides. 


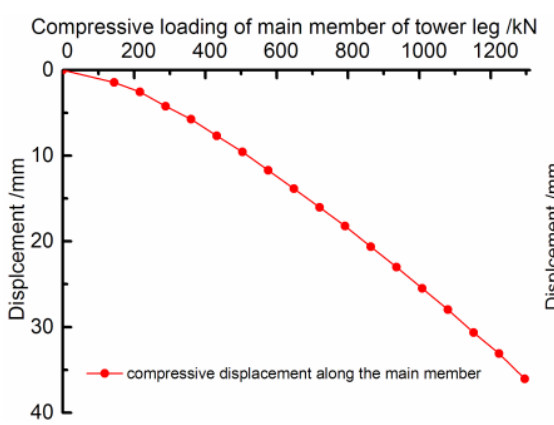

(a) Main member of tower leg

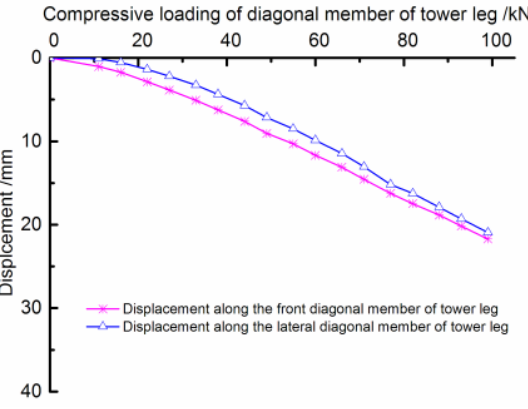

(b) Diagonal member of tower leg

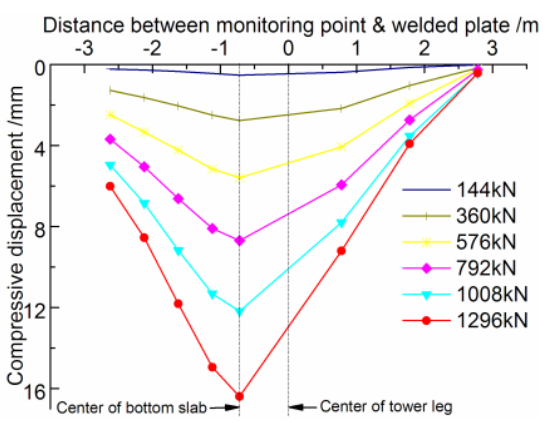

(c) Surface displacement monitoring point

Fig. 4 Load-displacement curves of the compressive tests with loading direction in accord with the angle of tower leg

\section{Conclusions}

Test results indicate that the ultimate tensile bearing capacity of the foundation is 1.1 times that of the design value, and the ultimate compressive bearing capacity is 1.8 times that of the design value. The maximum surface displacement is located at the center of the bottom slab's lath rather than the center of welded plate on the top. During the tests, no collapse between section steel scaffolds and concrete laths appears. The eccentric assembled foundations satisfy the design requirements and can be applied in practical projects.

This paper is supported by fund of Science and Technology Project of State Grid Corporation of China (GCB17201400134).

\section{References}

[1] China Electric Power Research Institute Investigation Report of Applications of the Assembled Tower Foundation in Power Transmission Lines Beijing: China Electric Power Research Institute, 2013

[2] Qian Zengzhen, Lu Xianlong, Ding Shijun Experimental study of assembly foundation for transmission line tower in Taklimakan desert, Rock and Soil Mechanics, 2011, 32 (8): 2359-2365.

[3] Cheng Yongfeng, Ding Shijun Prototype tests of assembly foundation of transmission line in aeolian sand area, Rock and Soil Mechanics, 2013, 33 (11): 3230-3236.

[4] A.C.C.F. Sieira, D.M.S. Gerscovich, A.S.F.J. Sayao. Displacement and load transfer mechanisms of geogrids under pullout condition. Geotextiles and Geomembranes. 2009, 27(1): 241-253.

[5] Infrastructure Department, State Grid Corporation of China, Technologies of Mechanized Construction of the Whole Process of Transmission Lines (Design Part) Beijing: China Electric Power Press, 2015.

[6] Industrial Standard of the People's Republic of China Technical Regulations for the Design of Foundations of Overhead Transmission Lines (DL/T 5219-2014) Beijing: China Electric Power Press, 2014.

[7] Wang Yanmin, Zhang Kebao Applications of Eccentric Foundations in Transmission Lines, Electric Power Construction, 19909, 11(10): 69.

[8] Bai Qiang, Zeng Erxian, Zhang Yi, et al. Optimal Eccentricity Numerical Analysis of Pad and Eccentric Chimney Foundation for Transmission Towers, Electric Power Survey \& Design, 2014, 6, 52-55. 